\title{
ANALISIS STRATEGI PENERJEMAHAN PADA FILM 'GOOD WILL HUNTING' KE DALAM BAHASA INDONESIA
}

\author{
Nova Jayanti Harahap \\ Dosen Tetap Sekolah Tinggi Ilmu Ekonomi Labuhan Batu, Sumatera Utara
}

novazhrp@gmail.com

\begin{abstract}
ABSTRAK
Penelitian ini bertujuan untuk mengkaji strategi penerjemahan pada terjemahan subtitle bahasa Indonesia dalam film 'Good Will Hunting'. Masalah penelitian ini adalah Strategi penerjemahan apa yang paling sering digunakan dalam hasil penerjemahan subtitle Inggris - Indonesia dalam film 'Good Will Hunting?' dan Bagaimana keakuratan Strategi Borrowing diterjemahkan ke dalam Bahasa Indonesia?. Sumber data dalam penelitian ini adalah subtitle film "Good Will Hunting”. Strategi yang digunakan dalam penelitian ini dikemukakan oleh Molina \& Albir (2002). Metode riset yang digunakan adalah metode kualitatif deskriptif. Sumber data penelitian ini adalah subtitle film Good Will Hunting. Data adalah 103 dalam teks subtitle yang terdiri 25 temuan (100\%) dan terjemahannya ke dalam BSa, pada BSu ditemukan 3 (12\%) Amplifikasi (Penambahan), 13 (52\%) Peminjaman (Borrowing), 6 (24\%) Deskripsi (Description), 2 (8\%) Padanan Lazim (Established Equivalence), 1 (4\%) Penerjemahan Harfiah (Literal Translation). Tiga belas strategi terjemahan tidak ditemukan dalam analisis terjemahan subtitle film yang terdiri dari Adaptasi (adaptation), Kalke (calque), Kompensasi (compensation), Kreasi diskursif (discursive creation), Generalisasi (generalization), Amplifikasi linguistik (linguistic amplification), Kompresi linguistik (linguistic compression), Modulasi (modulation), Partikularisasi (particularizaton), Reduksi (reduction), Subsitusi
\end{abstract} (subsitution), Transposisi (transposition), Variasi (Variation)

Kata Kunci: Keakuratan Makna, Strategi Terjemahan, Subtitle Film.

\section{ABSTRACT}

This study aims to edintify translation strategies in the translation of Indonesian subtitles in the film 'Good Will Hunting'. The problem with this research is what translation strategy is most often used in the translation of English-Indonesian subtitles in the film 'Good Will Hunting?' And how the accuracy of Borrowing Strategy is translated into Indonesian ?. The source of the data in this study is the subtitle of the film "Good Will Hunting". The strategy used in this study was put forward by Molina \& Albir (2002). The research method used is descriptive qualitative method. The data source of this research is the subtitle of the film Good Will Hunting. 103 in the text subtitle that consist of 25 findings (100\%) and the translation into BSa, in BSu found 3 (12\%) Amplifikasi (Penambahan), 13 (52\%) Peminjaman (Borrowing), 6 (24\%) Deskripsi (Description), 2 (8\%) Padanan Lazim (Established Equivalence), 1 (4\%) Penerjemahan Harfiah (Literal Translation). Thirteen 
translation strategies were not found in the translation analysis of subtitles consisting of Adaptasi (adaptation), Kalke (calque), Kompensasi (compensation), Kreasi diskursif (discursive creation), Generalisasi (generalization), Amplifikasi linguistik (linguistic amplification), Kompresi linguistik (linguistic compression), Modulasi (modulation), Partikularisasi (particularizaton), Reduksi (reduction), Subsitusi (subsitution), Transposisi (transposition), Variasi (Variation)

Keywords: Accuracy of Meanings, Strategy of Translation, Subtitles of Film.

\section{PENDAHULUAN}

Penterjemahan mengambil peran penting dalam komunikasi dan literature di era teknologi informasi dan komunikasi dewasa ini. Proses penerjemahan dari bahasa sumber (Bsu) ke dalam bahasa sasaran (Bsa) tidak terlepas dari pengaruh penerjemahan itu sendiri dan padanan kata dan makna dari bahasa sumber ke dalam bahasa sasaran. Dalam hal ini, Koller (1995: 196) menggambarkan sebagai berikut:

Translation can be understood as the result of a text reprocessing activity, but means of which a source language text is transposed into a target - language text. Between the resulting text in L2 (the target- language text) and the source text in L1 (the source- language text) there exists a relationship which can be designated as a translational, or equivalence relation" (Koller, 1995: 196).

Penerjemahan dapat dipahami sebagai hasil aktivitas memproses kembali sebuah teks, di mana bahasa sumber teks diubah ke dalam teks bahasa sasaran. Antara hasil terjemahan bahasa sasaran dan teks berbahasa sumber terdapat hubungan yang dapat ditentukan apakah memang sebatas terjemahan atau hubungan kesepadanan makna dan kata yang diterjemahkan.

Era komunikasi global membutuhkan bahasa terjemahan sesuai bahasa sasaran masyarakat agar pesan yang disampaikan dapat dipahami dan dimengerti. Produk non-sastra seperti buku teks ilmiah, jurnal, laporan penelitian, dokumen resmi dan produk sastra seperti film, lagu, novel, cerpen, roman dan puisi dapat menyebar dengan cepat ke seluruh penjuru dunia berkat peran penerjemahan atau alihbahasa dari bahasa sumber (bsu) ke dalam bahasa bahasa sasaran (bsa). Alvarez (1996: 1) menyatakan dengan tegas bahwa era saat ini adalah era komunikasi media massa secara global yang menggunakan perangkat multimedia di mana audiens atau masyarakat dunia saling berbagi teks terbaru berupa film, lagu, atau buku melampuai batasan budaya. "Globally, this is the age of mass communications, of multimedia experiences and a world where audiences demand the right to share the latest text, be it film, song, or book simultaneously across cultures" (Alvarez, 1996: 1).

Dari pernyataan Alvarez dapat kita pahami bahwa komunikasi masa tidak dapat dibendung dan berbagai produk media massa seperti film, lagu, buku dan sebagainya dengan cepat menyebar ke berbagai penjuru dunia. Penyebaran tersebut tidak terlepas dari peranan penerjemahan dari teks bahasa sumber (bsu) ke dalam teks bahasa sasaran (bsa). Salah satu aspek yang mempengaruhi proses penerjemahan adalah strategi penerjemahan kalimat idiom dan ideologinya yang mencakup domestifikasi, foreignisasi dan neutralisasi. Dalam 
menerjemahkan idiom dari bahasa sumber, seorang penerjemah mempertimbangkan penggunaan strategi tertentu agar hasil terjemahan diterima dan mudah dipahami oleh masyarakat pengguna bahasa sasaran. Salah satu objek yang menarik diteliti dan banyak diterjemahkan ke berbagai bahasa adalah subtitles film. Menurut Baker (1998: 244) subtitle film adalah hasil terjemahan bahasa ujar dari dialog bahasa sumber ke dalam bahasa sasaran yang ada dalam dialog film atau TV dalam bentuk teks tertulis yang ditampilkan secara silmultan di layar TV.

Beberapa studi sebelumnya yang meneliti tentang strategi penerjemahan salah satunya adalah strategi penerjemahan yang fokus pada identifikasi, analisis dan kaitan budaya dalam drama Afrika Guillaume Oyono Mbia's Plays oleh Joseph Che Suh (2005). Joseph menganalisis strategi hasil penerjemahan berdasarkan teori Mounin (1976), Nida (1982), dan Newmark (1988) yang terdiri dari delapan strategi yaitu (1) Adaptation, (2) Borrowing, (3) Communicative translation, (4) Addition, (5) Omission, (6) Globalization and localization, (7) Compensation, dan (8) footnotes. Di samping itu, Joseph juga menganalisis drama Guillaume Oyono Mbia's Plays dari segi mikro-tekstual yang terdiri dari ideophone, distorted words and names, loan words, proverbs, swearwords, allusions, forms of address, repetition dan stylistic calque.

Penelitian lain yang fokus pada strategi penerjemahan adalah penelitian yang dilaksanakan oleh Othman (2013). Ia meneliti peran micro dan macro level terjemahan dalam peribahasa berbahasa Arab modern. Dari segi micro level, ia fokus mengkaji semantic, sintaksis dan style yang dipadukan dengan macro level yang mengacu pada konteks sosial budaya masyarakat Arab yang mempengaruhi terbentuknya peribahasa yang dimaksud. Penelitian yang juga mengkaji micro level dilakukan oleh Wiwin Indiarti (2013). Ia fokus meneliti perbandingan proses penerjemahan budaya osing pada publikasi pariwisata dwibahasa kabupaten Banyuwangi.

Penelitian ini fokus mengkaji Analisis strategi penerjemahan borrowing dalam teks Terjemahan Indonesia dalam Subtitle Film 'Good Will Hunting' Alasan memilih penelitian ini adalah kajian terhadap penerjemahan borrowing dalam terjemahan Inggris - Indonesia dalam subtitle film 'Good Will Hunting' belum pernah dilakukan. Kedua, banyak bahasa ujar dalam teks subtile Indonesia yang sangat menarik diteliti dari aspek borrowing seperti ideopohones, distorted names, loan words, dan lain-lain. Ketiga, penelitian ini mengungkap strategi apa yang digunakan oleh si penerjemah dalam menerjemahkan subtitle yang terdapat dalam film berbahasa Inggris yang dialihbahasakan ke dalam bahasa Indonesia dalam teks subtitle film berjudul 'Good Will Hunting'.

\section{Rumusan Masalah}

Mengacu pada pendahuluan, peneliti merumuskan masalah sebagai berikut:

1. Strategi penerjemahan apa yang paling sering digunakan dalam hasil penerjemahan subtitle Inggris - Indonesia dalam film 'Good Will Hunting?'

2. Bagaimana keakuratan Strategi Borrowing diterjemahkan ke dalam Bahasa Indonesia? 


\section{KERANGKA TEORI}

\section{a. Penerjemahan}

Ada beberapa definisi mengenai penerjemahan. Berikut peneliti menyajikan beberapa diantaranya. Newmark (1981: 7) mengatakan terjemahan adalah seni dan kemampuan. Menurutnya terjemahan merupakan suatu keahlian yang meliputi usaha mengganti pesan atau pernyataan tertulis dalam suatu bahasa dengan pesan atau pernyataan yang sama dalam bahasa lain. Translation is in an art and a skill. Translation is a craft consisting in the attempt to replace a written message and/or statement in one language by the same message and/or statement in another language.

Catford (1965: 20-21) menyebutkan penerjemahan ialah mengganti teks pada bahasa sumber dengan teks lain yang sepadan dalam bahasa sasaran. The replacement of textual material in one language (SL) by equivalent textual material in another language (TL) and the term equivalent is a clearly a key term.

Larson (1984: 3) mendefinisikan penerjemahan sebagai pengalihan makna dari bahasa sumber ke dalam bahasa sasaran melalui tiga langkah pendekatan, yakni: 1) mempelajari leksikon, struktur gramatikal, situasi komunikasi, dan konteks budaya dari teks bahasa sumber; 2) menganalisis teks bahasa sumber untuk menemukan maknanya; dan 3) mengungkapkan kembali makna yang sama dengan menggunakan leksikon dan struktur gramatikal yang sesuai dalam bahasa sasaran.

Bell (1991: 10) mengatakan penerjemahan melibatkan bidang linguistik dari kedua bahasa yaitu bahasa sumber (BSu) dan bahasa sasaran (BSa), yang mencakup teori makna (semantik), metode, prosedur, dan teknik penerjemahan, dan bidang ilmu teks yang diterjemahkan. Dengan demikian penerjemahan dapat melibatkan beberapa pihak terkait sesuai dengan teks yang akan diterjemahkan. Hal ini disebabkan seorang penerjemah tidak akan menguasai semua disiplin ilmu yang terkait dengan penerjemahan.

Berdasarkan definisi oleh para pakar penerjemahan tersebut, dapat disepakati bahwa penerjemahan merupakan suatu proses pentransferan makna pesan dalam bahasa sumber (BSu) ke bahasa sasaran (BSa) dengan mengutamakan penyepadanan, sehingga nantinya menjadi produk terjemahan yang baik sehingga mudah dipahami oleh pembaca (target reader). Kemudian, untuk dapat menerjemahkan sutu teks yang sepadan dengan $\mathrm{BSu}$ hendaknya penerjemah melibatkan metode, prosedur, teknik penerjemahan, serta pemahaman makna (semantik) dan penguasaan pada bidang ilmu teks yang diterjemahkannya.

Menurut Larson (1989:6), terjemahan yang terbaik adalah terjemahan yang menggunakan bentuk wajar bahasa sasaran; menyampaikan sebanyak mungkin makna yang sama kepada penutur bahasa sasaran seperti yang dimengerti oleh penutur bahasa sumber; mempertahankan dinamika teks bahasa sumber, artinya menyajikan terjemahan sedemikian rupa sehingga dapat membangkitkan respons pembaca, dan diharapkan sama seperti teks sumber membangkitkan pembacanya.

Dengan demikian, Penerjemahan merupakan pengalihan suatu pesan dari BSu ke BSa dengan mengindahkan gaya dan bentuk yang ada pada BSa guna memperoleh kesepadan makna yang utuh. Jadi, terjemahan dikatakan baik apabila pesan yang disampaikan tetap mempertahankan dinamika dari bahasa sumber dan dalam bentuk sewajar mungkin kepada pembaca. 
Penerjemahan dilakukan dengan berbagai tujuan, namun tujuan terakhir penerjemahan adalah untuk mencapai kesepadanan pada tingkat teks, bukan kesepadanan tingkat kata atau frasa (Baker, 1992: 11).Kridalaksana (2008:181) menambahkan bahwa penerjemahan merupakan pengalihan amanat antar budaya atau antar bahasa dalam tataran gramatikal dan leksikal dengan maksud, efek atau wujud yang sebisa mungkin tetap dipertahankan. Oleh sebab itu, untuk mencapai tingkat kesepadanan penerjemah perlu menguasai pengetahuan yang lebih khusus mengenai dua bahasa, tidak hanya hal-hal internal yang terdapat pada bahasa, namun juga hal-hal eksternal.

\section{b. Strategi Penerjemahan}

Teknik penerjemahan ialah cara yang digunakan untuk mengalihkan pesan dari BSu ke BSa, diterapkan pada tataran kata, frasa, klausa maupun kalimat. Menurut Molina dan Albir (2002), teknik penerjemahan memiliki lima karakteristik:

1. Teknik penerjemahan mempengaruhi hasil terjemahan.

2. Teknik diklasifikasikan dengan perbandingan pada teks BSu.

3. Teknik berada tataran mikro.

4. Teknik tidak saling berkaitan tetapi berdasarkan konteks tertentu.

5. Teknik bersifat fungsional.

Setiap pakar memiliki istilah tersendiri dalam menentukan suatu teknik penerjemahan, sehingga cenderung tumpang tindih antara teknik dari seorang pakar satu dengan yang lainnya. Teknik yang dimaksud sama namun memiliki istilah yang berbeda. Dalam hal keberagaman tentunya hal ini bersifat positif, namun di sisi lain terkait penelitian akan menimbulkan kesulitan dalam menentukan istilah suatu teknik tertentu. Oleh karena itu, dalam hal ini penulis menggunakan 18 teknik penerjemahan yang dikemukakan oleh Molina dan Albir. Selain untuk keseragaman, teknik yang dikemukakan Molina dan Albir telah melalui penelitian kompleks dengan mengacu dan membandingkan dengan teknik-teknik penerjemahan yang telah ada dari pakar penerjemahan sebelumnya. Berikut 18 teknik penerjemahan tersebut,

\section{1) Adaptasi (adaptation),}

Teknik ini dikenal dengan teknik adaptasi budaya. Teknik ini dilakukan dengan mengganti unsur-unsur budaya yang ada BSu dengan unsur budaya yang mirip dan ada pada BSa. Hal tersebut bisa dilakukan karena unsur budaya dalam BSu tidak ditemukan dalam BSa, ataupun unsur budaya pada BSa tersebut lebih akrab bagi pembaca sasaran. Teknik ini sama dengan teknik padanan budaya.

Contoh:

\begin{tabular}{|l|l|}
\hline Bsu & Bsa \\
\hline as white as snow & seputih kapas \\
\hline
\end{tabular}


2) Amplifikasi (amplification),

Teknik penerjemahan dengan mengeksplisitkan atau memparafrase suatu informasi yang implisit dalam BSu. Teknik ini sama dengan eksplisitasi, penambahan, parafrasa eksklifatif. Catatan kaki merupakan bagian dari amplifikasi. Teknik reduksi adalah kebalikan dari teknik ini.

Contoh:

\begin{tabular}{|l|l|}
\hline Bsu & BSa \\
\hline Ramadhan & Bulan puasa kaum muslim \\
\hline
\end{tabular}

3) Peminjaman (borrowing),

Teknik penerjemahan yang dilakukan dengan meminjam kata atau ungkapan dari BSu. Peminjaman itu bisa bersifat murni (pure borrowing) tanpa penyesuaian atau peminjaman yang sudah dinaturalisasi (naturalized borrowing) dengan penyesuaian pada ejaan ataupun pelafalan. Kamus resmi pada BSa menjadi tolok ukur apakah kata atau ungkapan tersebut merupakan suatu pinjaman atau bukan.

Contoh:

\begin{tabular}{|l|l|l|}
\hline BSu & Bsa & peminjaman \\
\hline Mixer & Mixer & murni \\
\hline Mixer & Mikser & alamiah \\
\hline
\end{tabular}

4) Kalke (calque),

Teknik penerjemahan yang dilakukan dengan menerjemahkan frasa atau kata BSu secara literal. Teknik ini serupa dengan teknik penerimaan (acceptation).

Contoh:

\begin{tabular}{|l|l|}
\hline Bsu & BSa \\
\hline Directorate General & Direktorat Jendral \\
\hline
\end{tabular}

5) Kompensasi (compensation),

Teknik penerjemahan yang dilakukan dengan menyampaikan pesan pada bagian lain dari teks terjemahan. Hal ini dilakukan karena pengaruh stilistik (gaya) pada BSu tidak bisa di terapkan pada BSa. Teknik ini sama dengan teknik konsepsi.

Contoh:

\begin{tabular}{|l|l|}
\hline Bsu & BSa \\
\hline A pair of scissors & Sebuah gunting \\
\hline
\end{tabular}

6) Deskripsi (description),

Teknik penerjemahan yang dilterapkan dengan menggantikan sebuah istilah atau ungkapan dengan deskripsi bentuk dan fungsinya. 
Contoh:

\begin{tabular}{|l|l|}
\hline Bsu & BSa \\
\hline panettone & kue tradisional Italia yang dimakan pada saat Tahun Baru \\
\hline
\end{tabular}

7) Kreasi diskursif (discursive creation),

Teknik penerjemahan dengan penggunaan padanan yang keluar konteks. Hal ini dilakukan untuk menarik perhatian calon pembaca. Teknik ini serupa dengan teknik proposal. Contoh:

\begin{tabular}{|l|l|}
\hline BSu & Bsa \\
\hline The Godfather & Sang Godfather \\
\hline
\end{tabular}

8) Padanan lazim (establish equivalence),

Teknik dengan penggunaan istilah atau ungkapan yang sudah lazim (berdasarkan kamus atau penggunaan sehari-hari). Teknik ini mirip dengan penerjemahan harfiah. Contoh:

\begin{tabular}{|l|l|}
\hline Bsu & BSa \\
\hline Ambiguity & ambigu \\
\hline
\end{tabular}

9) Generalisasi (generalization),

Teknik ini menggunakan istilah yang lebih umum pada BSa untuk BSu yang lebih spesifik. Hal tersebut dilakukan karena BSa tidak memiliki padanan yang spesifik. Teknik ini serupa dengan teknik penerimaan (acceptation).

Contoh:

\begin{tabular}{|l|l|}
\hline Bsu & BSa \\
\hline Penthouse, mansion & Tempat tinggal \\
\hline
\end{tabular}

10) Amplifikasi linguistik (linguistic amplification),

Teknik penerjemahan yang dilakukan dengan menambahkan unsur-unsur linguistik dalam BSa. Teknik ini lazim diterapkan pada pengalihbahasaan konsekutif dan sulih suara. Contoh:

\begin{tabular}{|l|l|}
\hline BSu & Bsa \\
\hline No way & De ninguna de las maneras (Spain) \\
\hline
\end{tabular}

11) Kompresi linguistik (linguistic compression),

Teknik yang dilakukan dengan mensintesa unsur-unsur linguistik pada BSa. Teknik ini merupakan kebalikan dari teknik amplifikasi linguistik. Teknik ini lazim digunakan pada pengalihbahasaan simultan dan penerjemahan teks film. 
Contoh:

\begin{tabular}{|l|l|}
\hline Bsu & BSa \\
\hline Yes so what? & Y? (Spain) \\
\hline
\end{tabular}

12) Penerjemahan harfiah (literal translation),

Teknik yang dilakukan dengan cara menerjemahkan kata demi kata dan penerjemah tidak mengaitkan dengan konteks.

Contoh:

\begin{tabular}{|l|l|}
\hline Bsu & Bsa \\
\hline Killing two birds with one stone & Membunuh dua burung dengan satu batu \\
\hline
\end{tabular}

13) Modulasi (modulation),

Teknik penerjemahan yang diterapkan dengan mengubah sudut pandang, fokus atau kategori kognitif dalam kaitannya dengan BSu. Perubahan sudut pandang tersebut dapat bersifat leksikal atau struktural.

Contoh:

\begin{tabular}{|l|l|}
\hline Bsu & Bsa \\
\hline Nobody doesn't like it & Semua orang menyukainya \\
\hline
\end{tabular}

14) Partikularisasi (particularizaton),

Teknik penerjemahan dimana penerjemah menggunakan istilah yang lebih konkrit, presisi atau spesifik, dari superordinat ke subordinat. Teknik ini merupakan kebalikan dari teknik generalisasi.

Contoh:

\begin{tabular}{|l|l|}
\hline Bsu & BSa \\
\hline air transportation & pesawat \\
\hline
\end{tabular}

15) Reduksi (reduction),

Teknik yang diterapkan dengan penghilangan secara parsial, karena penghilangan tersebut dianggap tidak menimbulkan distorsi makna. Dengan kata lain, mengimplisitkan informasi yang eksplisit. Teknik ini kebalikan dari teknik amplifikasi.

Contoh:

\begin{tabular}{|l|l|}
\hline Bsu & BSa \\
\hline SBY the president of republic of Indonesia & SBY \\
\hline
\end{tabular}


16) subsitusi (subsitution),

Teknik ini dilakukan dengan mengubah unsur-unsur linguistik dan paralinguistik (intonasi atau isyara).

Contoh: Bahasa isyarat dalam bahasa Arab, yaitu dengan menaruh tangan di dada diterjemahkan menjadi Terima kasih.

17) transposisi (transposition),

Teknik penerjemahan dimana penerjemah melakukan perubahan kategori gramatikal. Teknik ini sama dengan teknik pergeseran kategori, struktur dan unit. Seperti kata menjadi frasa. Contoh:

\begin{tabular}{|l|l|}
\hline Bsu & Bsa \\
\hline adept & Sangat terampil \\
\hline
\end{tabular}

\section{Variasi (Variation)}

Teknik penerjemahan yang mengganti unsur-unsur linguistik atau paralinguistik yang mempengaruhi variasi linguistik. Misalnya perubahan textual tone, style, geographical dialect, dan social dialect.

Contoh:

\begin{tabular}{|l|l|}
\hline Bsu & Bsa \\
\hline Give it to me now! & Berikan barang itu ke gue sekarang! \\
\hline
\end{tabular}

\section{METODE PENELITIAN}

Data penelitian ini adalah ujaran dan terjemahannya (subtitle) dalam film Good Will Hunting yang terdiri dari kata, frasa, klausa maupun kalimat. Film Good Will Hunting tersebut berdurasi 2:6:33 (2 jam 6 menit 33 detik) yang disutradarai oleh Gus Van Sant. Film tersebut bergenre drama romantis karangan Matt Damon dan en Affleck, difilmkan dan rilis filmnya pertama kali di Amerika Serikat pada 9 Januari 1998. Sumber data penelitian ini adalah situs subscene.com.

\section{Metode Pengumpulan Data}

Miles dan Huberman (2014: 10) mengatakan reduksi data merujuk pada proses penyeleksian, pemfokusan, penyederhanaan, pengabstraksian, dan pentransformasian data yang terdapat pada catatan lapangan maupun transkrip, dalam penelitian ini yang diuraikan sebagai berikut.

\section{a. Selecting}

Peneliti harus bertindak selektif, yaitu menentukan dimensi-dimensi yang lebih penting, hubungan-hubungan mana yang lebih bermakna, informasi apa yang dapat dikumpulkan 
dan dianalisis. Informasi tersebut berhubungan dengan kohesi gramatikal dan penggunaannya dalam sebuah kalimat, serta dan pergeseran terjemahan kohesi gramatikal yang sering terjadi pada sebuah teks. Peneliti mengumpulkan seluruh informasi tersebut melalui subtitle dan mengutip dari sumber-sumber bacaan yang terpercaya yang berkaitan dengan penelitian ini seperti buku, jurnal, internet untuk memperkuat penelitian.

b. Focusing

Pada tahap ini, peneliti memfokuskan data yang berhubungan dengan rumusan masalah penelitian. Tahap ini merupakan kelanjutan dari tahap seleksi. Pertama, fokus data yaitu pada bentuk terjemahan subtitle pada film Good Will Hunting dalam bahasa Indonesia. Strategi penerjemahan jenis apa yang terjadi pada terjemahan subtitle film Good Will Hunting. Data yang diambil berdasarkan teori dan konsep yang relavan. Kedua, berkenaan dengan strategi yang digunakan pada subtitle film Good Will Hunting. Data dianalisis berdasarkan teori dan konsep yang relavan seperti teori Catford (1965).Disamping itu, peneliti mampu melakukan analisis strategi terjemahan karena peneliti menguasai konsep penggunaan strategi penerjemahan yang terdapat pada subtitle yang sudah diterjemahkan oleh penulis dalam sebuah film baik dalam bahasa Inggris (Bsu) maupun bahasa Indonesia (Bsa). Dengan alasan tersebut di atas, maka analisis ini dapat dilakukan oleh peneliti sendiri.

c. Abstracting

Abstraksi merupakan usaha yang dilakukan untuk membuat inti rangkuman, proses, dan pernyataan-pernyataan yang perlu dijaga sehingga tetap berada di dalamnya. Pada tahap ini, data yang telah terkumpul dievaluasi, khususnya yang berkaitan dengan kualitas dan kecukupan data.

\section{d. Simplifying dan transforming}

Data dalam penelitian ini selanjutnya disederhanakan dalam berbagai cara, yakni melalui ringkasan dan uraian singkat, menggolongkan data dalam satu pola yang lebih luas, dan sebagainya. Untuk menyederhanakan data, peneliti mengumpulkan data yang terdapat pada novel pada terjemahan novel Good Will Hunting dalam tabel dan disesuaikan dengan penelitian yang terkait yaitu bentuk strategi terjemahan dalam subtitle tersebut.

\section{Teknik Analisis Data}

Analisis data dilakukan bersamaan dengan proses pengumpulan data. Menurut Miles dan Huberman (2014: 12) analisis data dilakukan dengan tiga tahap model interaktif, yaitu reduksi data, penyajian data, dan verifikasi. Tiga tahap tersebut berlangsung secara stimultan.

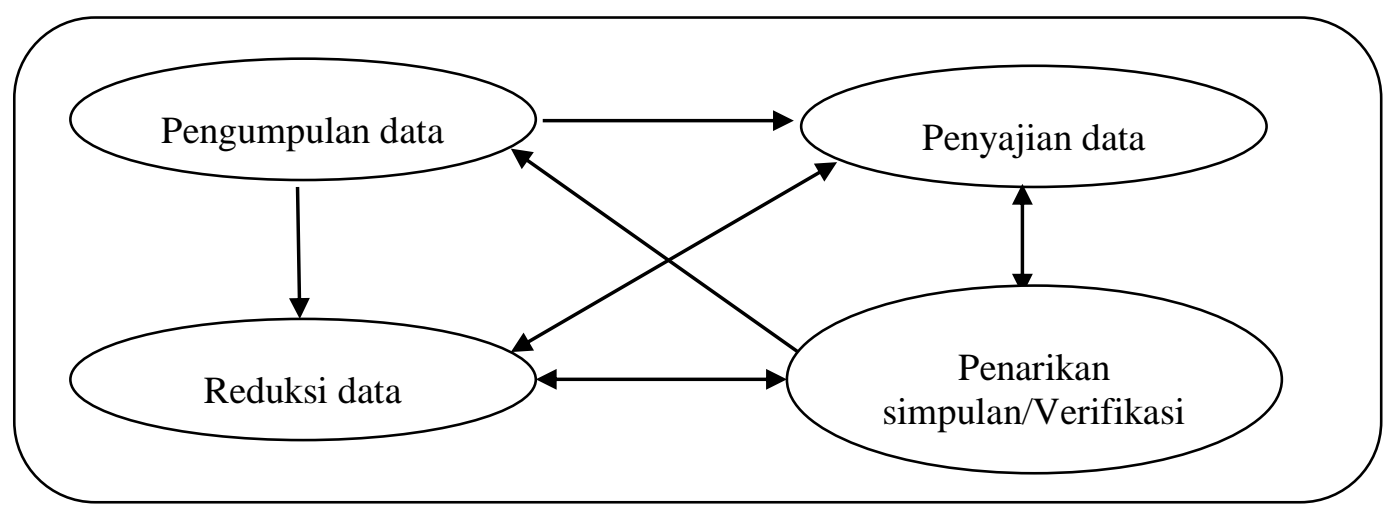




\section{Menyajikan Data (Data Display)}

Dalam menyajikan data terdapat beberapa tahap, yaitu:

a. Menyajikan jumlah total frekuensi dan persentase dari temuan data ketidaksepadanan makna yang ditemukan pada teks ujaran subtitle film Good Will Hunting berbahasa Indonesia.

b. Mendeskripsikan hasil temuan secara detil.

c. Menyajikan temuan ketidaksepadanan makna disertai makna sepadan yang direkomendasikan berdasarkan 18 strategi menurut Molina dan Albir (2002) disertai dengan deksripsinya.

\section{Membuat simpulan (Conclusion drawing/verification).}

Simpulan disusun sebagai langkah terakhir, setelah semua data sudah dianalisis, sudah dijelaskan dan sudah disajikan dalam kuantifikasi sederhana seperti frekuensi dan persentase serta sudah diperbaiki dengan menggunakan 18 strategi terjemahan makna yang direkomendasikan. Kesimpulan merupakan jawaban puncak dari rumusan masalah yang ditetapkan di bab sebelumnya. Proses simpulan ini terdiri dari beberapa tahap:

a. Menyimpulkan jumlah frekuensi dan persentase temuan jenis-jenis strategi yang digunakan, disertai deskripsi temuan secara detil.

b. Menyimpulkan strategi yang direkomendasikan yang sesuai digunakan untuk memperbaiki makna dalam subtitle tersebut.

\section{PEMBAHASAN}

\section{Strategi yang Digunakan untuk Memperbaiki Keakuratan Makna.}

Berdasarkan dari 18 hasil temuan strategi terjemahan borrowing yang telah dideskripsikan pada hasil dan pembahasan di atas, dibutuhkan strategi yang digunakan untuk memperbaiki keakuratan makna. Strategi yang digunakan adalah delapan belas strategi menurut Molina dan Albir (2002) .Strategi tersebut digunakan untuk memperbaiki tiap-tiap keakuratan makna agar makna kata pada teks ujaran film Me Before You yang tidak akurat menjadi akurat maknanya.

Tabel 1

Penggunaan Strategi yang Direkomendasikan (disarankan)

\begin{tabular}{clcc}
\hline NO. & \multicolumn{1}{c}{ STRATEGI } & $\begin{array}{c}\text { Frekuensi Penggunaan } \\
\text { Strategi }\end{array}$ & $\%$ \\
\hline 1 & Adaptasi (Adaptation) & - & - \\
2 & Amplifikasi (Penambahan) & 3 & 12 \\
3 & Peminjaman (Borrowing) & 13 & 52 \\
4 & Kalke (Calque) & - & - \\
5 & Kompensasi (Compensation) & - & - \\
6 & Deskripsi (Description) & 6 & 24 \\
7 & Kreasi Diskursif (Discursive Creation) & - & -
\end{tabular}


8 Padanan Lazim (Established Equivalence)

2

4

9 Generalisasi (Generalization)

10 Amplifikasi Linguistik (Linguistics

Amplification)

11 Kompresi Linguistik (Linguistics

Compression)

12 Penerjemahan Harfiah (Literal Translation)

13 Modulasi (Modulation)

14 Partikularisasi (Particularization)

15 Reduksi (Reduction)

16 Substitusi (Substitution)

17 Transposisi (Transposition)

18 Variasi (Variation)

Total

25

100

Untuk deskripsi lebih detil dan mendalam beberapa temuan jenis-jenis strategi yang digunakan dalam subtitle film Good Will Hunting berbahasa Indonesia, penulis akan mendeskripsikan sebagai berikut.

1. Amplifikasi (Penambahan)

Dari 25 data temuan, jenis strategi penerjemahan amplifikasi ditemukan tiga kali yaitu pada kata American, Natal, you. Dalam teks ujaran film, hal tersebut ditemukan pada saat Prof. Gerald Lambeau berbicara dengan Will mengenai pelajaran yang sedang mereka diskusikan di dalam kelas.

Bsu: there are many American at the campus, aspecially here.

Bsa: Banyak warga negara Amerika di kampus, terutama disini

Kata American pada data (1) kata Amerika diterjemahkan menjadi warga negara Amerika di sini dimaksudkan untuk memperjelas informasi tanpa mengubah pesan yang terkandung dalam kata tersebut, dengan tetap menggunakan Amerika, terjemahan tersebut berpotensi membingungkan penonton karena akan penasaran bertanya-tanya apa itu Amerika. Menyatakan tempat, orang atau nama atau yang lainnya. Untuk menghindari kebingungan penonton terkait makna American, maka disarankan menggunakan strategi dengan menambahkan keterangan tambahan pada terjemahannya disamping tetap mempertahankan frasa American tersebut. Keterangan tambahan tersebut bisa diterjemahkan menjadi: warga negara Amerika 


\section{Peminjaman (Borrowing)}

\section{Data 1:}

Bsu: "how dare you tell him what to do? You don't even pay enough attention to know what he's going through in Social studies class!" Olive shouted this at him while Christopher remained silent, a smmirk on his face.

Bsa: "Beraninnya kau menyuruhnya! Kau bahkan tidak cukup perhatian terhadap apa yang dilakukannya di kelas social studies! Olive meneriakinya.

\section{Data 2}

Bsu: Passing by the Caldwells' farm, he saw a handwritting sign, FREE KITTENS, and he arrived at the pharmacy the next day with a kitty-litter box, cat food, and a small black kitten, whose feet were white, as though it had walked through a bowl of whipped cream.

Bsa: Melewati lahan pertanian Caldwell, dia mellihat tanda yang bertuliskan "ANAK KUCING GRATIS" dan tiba di apotek keesokannya dengan kotak tempat kotoran anak kucing, makanan kucing, dan anak kucing berwarna hitam berkaki purih seolah dia baru saya berjalan dengan mangkuk berisi whipped cream.

Data di atas menunjukkan penggunaan strategi borrowing untuk menerjemahkan 'social studies'. Menurut penjelasan di laman Wikipedia yang diakses pada 30 nopember 2018, social studies is the integrated study of the social sciences and humanities to promote civic competence. It is most commonly recognized as the name of a course or set of courses tought in elementary, middle, and secondary schools. These courses are interdisciplinary and draw upon various fields, including sociology, political science, history, economics, religious studies, geography, psychology, antropology and civic'. Mengacu pada penjelasan itu, 'social studies' dalam Bsa sering disebut sebagai 'ilmu sosial'. Selama ada padanan istilah asing dalam Bsa, penerjemah sebaiknya menggunakan istilah Bsa itu agar mudah dipahami oleh pembaca Bsu.

Data dua strategi yang digunakan dianggap tepat. 'whipped cream' adalah bahan pelengkap makanan yang biasa digunakan untuk menghias kue, minuman dan eskrim. Bahan makanan ini sudah banyak dijual di pasar Indonesia dengan nama 'whipped cream'.

\section{Deskripsi (Description)}

Data yang menggunakan Strategi terjemahan deskripsi ditemukan sebanyak enam kali yaitu meliputi: Val D'isere, Des Hommes et des dieux, Place d'auphine, job center, westcoast, Pont Neuf yang diterjemahkan ke dalam Bahasa Indonesia secara utuh, tanpa ada perubahan dan adaptasi baik lafal, ejaan maupun struktur kata. Penggalan-penggalan teks ujar berikut ini adalah bukti menunjukkan temuan-temuan tersebut.

\section{4.}

Bsu: Put on a smile and head back to the job center.

Bsa: Pasang senyum dan kembalilah ke job center

Sementara pada data (2) frasa job center diterjemahkan ke dalam Bahasa Indonesia tetap menggunakan Bsu-nya yaitu mempertahankan frasa job center tanpa terjemahan padanan 
kata semakna yang ada dalam Bahasa Indonesia. Di Indonesia, job center bisa semacam job fair atau 'bursa kerja'. Yang menjadi pokok masalah adalah, antara job center dengan job fair/bursa kerja maknanya sangat berbeda. Job center dikenal di negara-negara Eropa dan Amerika berfungsi sebagai pusat biro jasa lowongan kerja atau juga sebagai perantara: yang butuh pekerja datang ke job center, yang butuh pekerjaan datang ke job center. Jadi di sini job center berperan sebagai perantara resmi dan beroperasi di kantor resmi. Dalam konteks film, itu ditunjukkan ketika Sean datang ke job center dan menanyakan apakah tersedia lowongan kerja (apapun itu) kepada salah satu karyawan biro job center yang bernama Sayeed.

Di sana, siapa saja yang membutuhkan tenaga kerja, baik itu pihak perusahaan, toko, pedagang kelontong, restoran, pemilik kebun buah atau rumah tangga butuh tenaga kerja maka cukup mendaftarkannya di biro jasa job center tersebut. Kemudian, biro jasa job center tersebut menawarkan kepada orang-orang yang datang butuh pekerjaan. Mana lowongan kerja tersedia cocok, bisa diambil. Misalnya, ada rumah tangga yang sibuk, butuh pembantu bersih-bersih rumah, maka pemilik rumah mendaftarkan di job center. Kemudian pihak biro jasa job center menawarkan kepada para pencari kerja yang datang. Hal seperti itu umum di sana. Bahkan sekadar pemetik buah, pekerja sales, pekerja cuci motor dll ada di job center.

Berbeda dengan job fair atau 'bursa kerja' yang digelar tidak setiap hari. Musiman. Sebulan sekali atau setahun sekali. Rata-rata yang memasang lowongan pun perusahaan menengah ke atas, berbeda dnegan job center yang mencakup semuanya dari perusahaan menengah ke atas hingga unit-unit kecil seperti sekadar pembantu rumah tangga, pekerja usaha cuci motor, pekerja pemetik buah dll. Jadi, kata job center disarankan diterjemahkan dengan 'pusat lowongan kerja'. Atau jika pun tetap mempertahankan kata job center disertai keterangan tambahan menjadi: job center (pusat lowongan kerja).

5. Padanan Lazim (Established Equivalence),

Bsu: She is making appleasure from the season's last apples, and the smell reaches him briefly-sweet, familiar, it tugs at some ancient longing - before he goes out the door in his tweed jacket and tie

Bsa: Dia sedang membuat saus apel terakhir sisa musim ini dan aromanya menjangkau Hendry - aroma manis, familiar, dan menariknya dalam kerinduan akan masa lampau

-sebelum akhirnya dia melangkah keluar dari pintu dengan jacket wol dan dasinya.

Data di atas menunjukkan strategi terjemahan padanan lazim merujuk pada penerjemahan harfiah. Dalam konteks cerita 'tweed jacket' akan dikenakan Henry ke gereja, maka jenis 'jacket' yang dimaksud adalah jacket resmi. Jika diterjemahkan menjadi 'jaket' maka kesan resmi itu tidak dapat ditangkap oleh pembaca dalam Bsa. Dalam Bsa 'jaket' umumnya mengacu paa pakaian penahan dingin atau penahan angin. Sebaiknya penerjemah mempertimbangkan konteks cerita dan menerjemahkan 'tweer jacket' menjadi 'jas berbahan tweed' ata 'jas wol'. 


\section{Penerjemahan Harfiah (Literal Translation),}

Dari hasil analisis data, jenis Perbedaan Makna kata Bsu dan Bsa 1 kali. Yaitu: five hundred pounds. Berikut adalah bukti temuan dari makna pada penggalan ujaran teks film Good Will Hunting yang menujukkan hal itu:

Bsu: Her birthday card to him did not arrive last week, as it has, always on time, for the last twenty years. She writes him a note with the card. Sometimes a line or two syands out, as in the one last year when she mentioned that paul, a freshman in high school, had become obese. He word. "Matt has developed a full- blown problem now- at five hundred pounds, he is obese."

Bsa: Tak ada kiriman kartu ulang tahun darinya seminggu lalu, padahal selama dua puluh tahun ini, kartu ini selalu datang tepat waktu. Dia menuliskan ucapan di kartunya. Kadang hanya satau atau dua baris, seperti yang tertulis di kartunya setahun lalu, saat menyebutkan tentang Matt yang baru masuk SMA. Yang menjadi obesitas. Kalimatnya. " Matt sudah menggelembung sekarang - dengan lima ratus pon, dia obesitas."

Data di atas menunjukkan penggunaan strategi harfiah untuk menerjemahkan 'five hundred pounds' menjadi 'lima ratus pon'. Jika mempertimbangkan pembaca Bsa yang umumnya tidak menggunakan satuan ukuran 'pound' untuk mengukur berat badan, maka terjemahan itu dianggap kurang tepat. Pembaca sasaran umumnya menggunakan satuan ukuran 'kilogram' untuk mengukur berat badan. Sehingga terjemahan yang muncul yaitu ' 227 kilogram'. Dengan pertimbangan 1 pon setara dengan $0.454 \mathrm{~kg}$.

Dalam data di atas penerjemah salah menerjemahkan beberapa bagian kalimat seperti 'a line or two stand out' dan 'a full blown problem'. Yang pertama. ' a line or two stand out' seharusnya mengacu pada hal lain yang ditulis, selain ucapan selamat ulang tahun, dalam hal ini yang dimaksud adalah 'satu atau dua hal penting'. Sementara yang kedua,'a full blown problem' sebaiknya tidak diterjemahkan secara harfiah menjadi 'menggelembung'. Tetapi menjadi 'masalah berat badan'.

\section{SIMPULAN}

1. Setelah dianalisis strategi penerjemahan pada subtitle film Good Will Hunting dan terjemahannya berdasarkan terjemahan dan tingkat keakuratannya, maka ditarik kesimpulan temuan penelitian sebagai berikut:

Pada TSu, 103 data yang dianalisis terdiri dari 25 temuan (100\%) dan terjemahannya ke dalam BSa, pada BSu ditemukan 3 (12\%) Amplifikasi (Penambahan), 13 (52\%) Peminjaman (Borrowing), 6 (24\%) Deskripsi (Description), 2 (8\%) Padanan Lazim (Established Equivalence), 1 (4\%) Penerjemahan Harfiah (Literal Translation).

2. Keakuratan terjemahan subtitle film Good Will Hunting mengacu pada kesesuaian sistem, kaidah dan kosakata BSa; tidak terikat pada struktur BSu. Strategi terjemahan yang digunakan terasa lazim dan akrab bagi pembaca BSa. Dari 25 data temuan terdapat 3 (12\%) Amplifikasi (Penambahan), 9 (36\%) Peminjaman (Borrowing), 6 (24\%) 
Deskripsi (Description), 2 (8\%) Padanan Lazim (Established Equivalence), 1 (4\%) Penerjemahan Harfiah (Literal Translation) adalah akurat. Berdasarkan persentase tersebut, maka dapat disimpulkan bahwa strategi terjemahan borrowing dalam subtitle film Good Will Hunting baik.

\section{DAFTAR PUSTAKA}

Andreici, M.T. 2016. Translation of Phrasemes. Equivalence And Non-Equivalence.

Professional Communication And Translation Studies, West University of Timisoara, Romania. 9/2016 page 153-166.

Argeg, G. M. 2015. The Problems of Translating Medical Terms from English into Arabic. University of Durham. Disertasi.

Baker, Mona. 1992. In Other Words: A Coursebook on Translation. Routlege: London.

Bartrina, F. 2004. The Challenge of Researh in Audiovisual Translation. Topics in Audiovisual Translation. Ed. Orero, Pilar. Amsterdam: John Benjamins Publishing Company, 2004. 157-167.

Bell, Roger T. 1998. Translation and Translating: Theory and Practice. Longman: New York.

Bungin, H, B, 2005. Metodologi Penelitian Kuantitatif. Jakarta: Kencana Perdana Media Group.

Cambdridge Advanced Leaner's Dictionary. Third Edition. 2008. Cambridge University Press.

Catford. 1965. Pendapat Beberapa Tokoh Tentang Terjemahan. http://mitrapenerjemah.com/ihwal-terjemahan-dan-pendapat-dari-beberapatokoh.com. 30 September 2015 (13:50).

Catford, J.C. 1965. A Linguistic Theory of Translation. Oxford University Press: London.

Hornby, A. S. 2003. Oxford Advanced Learner's Dictionary. Oxford University Press: New York.

Kridalaksana, H. 2008. Kamus Linguistik (Edisi Keempat). Jakarta: PT. Gramedia Pustaka Utama.

Larson L. M. 1984. Meaning-Based Translation: A Guide to Cross-Language Equivalence. Second edition. Boston: University Press of America.

Miles M.B, Huberman A.M \& Saldana J. 2014. Qualittaive Data Analisys A Methods Sourcebook. Arizona State University: SAGE Pubblication Inc. 
Mukhtoraliyevna, Z. S. 2016. The Notion of Non-Equivalent Vocabulary in Linguistics. International Journal on Studies in English Language and Literature (IJSELL) Volume 4, Issue 7, July 2016, pp 70-72.

Newmark, P. 1988. Approaches to Translation. New York: Pergamon Press.

Othman, E. 2014. Translation Strategies Adopted by English Department Students in Coping with Non Equivalence Problems. Malang: Brawijaya University.

Wiwin, Indiarti. 2013. Non-Equivalence at Grammatical and Word Level and the Strategies to Deal with: A Case Study of English Translation into Persian. International Journal of Language and Linguistics ISSN 2374-8850 Vol. 3, No. 3; August 2016. pp 101-107 